\title{
Configuração da imagem do conceito de produtos ecologicamente corretos
}

\section{Configuration of the Image of the Concept of Environmentally Friendly Products}

\author{
Deonir DE TONI* \\ Fabiano LARENTIS ${ }^{* *}$ \\ Adilene Alvares MATTIA *** \\ Gabriel Sperandio MILAN***
}

\begin{abstract}
RESUMO
As imagens enquanto representações mentais são capazes de direcionar o comportamento das pessoas. Neste sentido, a compreensão de como são configuradas as imagens de produtos ecologicamente corretos é uma forma de melhor direcionar ações de comunicação que visem promover o consumo consciente destes produtos no mercado. Produtos ecologicamente corretos podem ser definidos como produtos que geram menos impacto ao meio ambiente que outros produtos similares. Geralmente são produtos fabricados com matérias-primas renováveis, são recicláveis, biodegradáveis, duráveis e são geralmente fabricados de forma sustentável. A partir do Método de Configuração de Imagem (MCI), foram entrevistadas 339 pessoas, sendo que 207 são estudantes de graduação e 132 são trabalhadores do setor produtivo com até o ensino médio completo. A partir da análise de conteúdo das respostas dos entrevistados, observa-se que o conceito de produtos ecologicamente corretos está fundamentalmente ligado a produtos saudáveis, sem agrotóxicos, sustentáveis e recicláveis, que preservam o meio ambiente e são capazes de proporcionar um futuro melhor e bem-estar à humanidade. No que tange à multidimensionalidade da imagem, os resultados indicam que as principais dimensões que formam o conceito são a simbólica, associada mais à consciência ambiental, e a funcional, ligada diretamente a produtos que consomem menos energia e saudáveis, com $44 \%$ e $28 \%$ das citações mais frequentes e salientes, respectivamente. No entanto, na comparação entre os grupos pesquisados, a dimensão funcional apresentou percentuais maiores para os trabalhadores na comparação com os estudantes. A partir do método proposto e dos resultados alcançados, é possível entender melhor como um conceito de um objeto pesquisado se configura e, com base nisso, direcionar estratégias e ações de comunicação que visem à promoção destes produtos como forma de melhorar a sustentabilidade do meio ambiente.
\end{abstract}

Palavras-chave: consumo consciente; produtos ecologicamente corretos; multidimensionalidade das imagens.

\footnotetext{
"Doutor em Administração (UFRGS). Professor da Universidade de Caxias do Sul (UCS). E-mail: dtoni2@ucs.br

*** Doutor em Administração (UFRGS). Professor da Universidade de Caxias do Sul (UCS). E-mail: flarenti@ucs.br

**** Doutora em Desenvolvimento Regional (UNISC). Professora da Universidade de Caxias do Sul (UCS). E-mail: aamattia@ucs.br

***** Doutor em Engenharia de Produção na área de Sistemas de Qualidade (UFRGS). Professor da Universidade de Caxias do Sul (UCS).E-mail: gsmilan@ucs.br
} 


\begin{abstract}
Images as mental representations are able to influence people's behavior. In this sense, understanding how the images are configured for environmentally friendly products is a way to better direct communication actions aimed at promoting consumer awareness of these products. Environmentally friendly products can be defined as products that generate less impact to the environment than other similar products. They are usually manufactured with renewable raw materials, are recyclable, biodegradable, durable, and are generally manufactured sustainably. From the angle of the Image Configuration Method (ICM), 339 people were interviewed, 207 being undergraduates and 132 workers from manufacture departments, with at most a high school degree. From the content analysis of the responses of the interviewees, it is observed that the concept of environmentally friendly products is fundamentally linked to healthy products without pesticides, sustainable and recyclable, preserving the environment, and capable of providing a better future and well-being to humanity. Regarding the multidimensionality, the results indicate that the main dimensions that form the concept are i) symbolic, associated with more environmental awareness, and ii) functional, linked directly to products that consume less energy and are healthy, with $44 \%$ and $28 \%$ of the most frequent and salient quotes, respectively. However, when comparing the groups surveyed, the functional dimension showed higher percentages for workers in comparison with students. From the proposed method and the results achieved, it is possible to better understand how a concept of a researched object configures itself and, on this basis, direct communication strategies and actions aimed at promoting these products as a way to improve the environmental sustainability.
\end{abstract}

Keywords: conscious consumption; environmentally friendly products; multidimensional images.

\section{Introdução}

As imagens enquanto representações constituem um dos materiais intelectuais mais importantes do homem, sendo capazes de influenciar e direcionar o seu comportamento, uma vez que se interpreta o mundo para, então, poder refletir sobre os seus objetos, mesmo que eles não estejam presentes. Por outro lado, a percepção de valor em produtos ecologicamente corretos se relaciona com a consciência ambiental, na medida em que esses produtos podem também impactar no bem-estar dos consumidores (LEITE, 2009).

A partir de uma ampla revisão da literatura, Croning et al. (2011) propõem uma agenda de pesquisa com onze diferentes direcionamentos no estudo do consumo consciente e sustentabilidade. Dentre estes, a busca de um entendimento maior das características do consumidor que podem afetar o comportamento do consumo de produtos ecologicamente corretos é apontado como um caminho importante de pesquisa.

Assim, compreender a imagem sobre o consumo consciente é um pressuposto básico para entender as atitudes do consumidor em relação à compra e ao consumo socialmente responsável. Este estudo, portanto, tem por objetivo compreender o processo de configuração de imagem de produtos ecologicamente corretos. Assim, um entendimento das imagens dos consumidores em relação a um objeto é uma forma de direcionar melhor as estratégias e ações de comunicação e, neste caso, de promoção destes produtos, uma vez que estimulam o bem-estar social e ambiental.

Produtos ecologicamente corretos podem ser definidos como produtos que geram menos impacto ao meio ambiente que outros produtos similares. Geralmente são produtos fabricados com matérias-primas renováveis, são recicláveis, biodegradáveis, duráveis e são geralmente fabricados de forma sustentável (OTTMAN, 2012). Na relação com a imagem, pode-se afirmar que o conceito de produtos ecologicamente corretos está relacionado à dimensão simbólica, manifestada predominantemente pela consciência ecológica; à dimensão racional, em que apresenta uma percepção focada na economia de recursos; à dimensão funcional, calcada na reutilização dos produtos e reciclagem; e à dimensão axiomática, em que manifesta um valor fundamentalmente baseado na vida saudável e no bem-estar social e individual. 
O estudo exploratório descritivo foi desenvolvido com uma amostra de 339 pessoas, sendo que $61,1 \%$ desta amostra é de estudantes e $36,8 \%$ de trabalhadores. A partir da utilização do Método de Configuração da Imagem (MCI), foi possível primeiro identificar os atributos formadores das representações do conceito de produtos ecologicamente corretos. Em um segundo momento, foi identificado como estes atributos estão organizados na mente dos entrevistados a partir da identificação da imagem central do conceito. Por fim, categorizaram-se os atributos de acordo com as dimensões identificadas na revisão da literatura.

Observa-se que consumo de produtos ecologicamente corretos ou produtos verdes é um caminho para o consumo consciente e, posteriormente, para o consumo sustentável. Desta forma, este estudo auxilia a melhor entender a configuração do conceito para posteriormente direcionar estratégias e ações de comunicação capazes de melhor divulgar o conceito e utilização (ou consumo) destes produtos.

Este artigo está dividido em seis seções. As seções 2 a 5 tratam da revisão da literatura sobre os temas, respectivamente: imagem, consumo consciente, produtos ecologicamente corretos e sua multidimensionalidade. A seção seguinte trata do Método de Configuração da Imagem e de como foi realizada a pesquisa. A seção 7 apresenta os resultados da pesquisa, enquanto a seção final apresenta algumas considerações finais sobre a pesquisa.

\section{Conceito de imagem e formas de organização das imagens na memória}

A imagem pode ser definida como um conjunto de representações, de impressões e de convicções de um objeto armazenado na memória e constitui um dos principais fatores impulsionadores do comportamento das pessoas. Segundo alguns autores (BOULDING, 1986; DOBNI e ZINKHAN, 1990; MOSCOVICI, 2000; MORGAN, 2000, dentre outros), o processo de compra e de consumo é fortemente influenciado pelas imagens que as pessoas têm sobre os produtos e/ou serviços e suas marcas e os seus respectivos preços. Dentre as diferentes perspectivas do entendimento de como as imagens estão organizadas na memória de um indivíduo, alguns pressupostos teóricos merecem destaque, como é o caso da Teoria das Representações Sociais e da Teoria do Núcleo Central.

A Teoria das Representações Sociais, inicialmente abordada por Moscovici (1978), é uma das principais teorias que explicam os processos de influências sociais e como os indivíduos adquirem e organizam seus modelos mentais (BREAKWELL, 2001). A Teoria das Representações Sociais apresenta a formação dos modelos mentais como um processo socialmente mediado. Sendo assim, o grupo social no qual o indivíduo convive e interage, o seu comportamento, o contexto organizacional e os canais de informação são compreendidos como agentes fortemente influenciadores na formação das imagens dos indivíduos.

Para Moscovici (2000) e Jodelet (1988), as representações sociais são um conjunto de convicções, de crenças, de valores e de conhecimentos amplamente compartilhados pelas pessoas e têm como finalidade tornar os eventos familiares, assegurando a possibilidade de compartilhamento da rede de significados que lhes for atribuída. Embora as representações sociais estejam relacionadas a outras formas de conhecimento social, tais como a ciência, a política, o conhecimento tecnológico, elas são geralmente distintas pela sua ampla disseminação na população e pela sua função prática no dia a dia das relações sociais. A maior diferença é que elas são geralmente faladas, informativas mais do que prescritivas.

Segundo Jodelet (2008), os sujeitos não podem ser concebidos como indivíduos isolados, mas sim como atores sociais ativos, influenciados por diferentes aspectos da vida cotidiana em uma triangulação "Eu-Outro-Objetos". O eu se define a partir da relação que o indivíduo mantém com o outro e também com os objetos que o rodeiam. A relação dos indivíduos com os objetos constitui um escopo de pesquisa interessante e é foco do trabalho.

A Teoria do Núcleo Central sugere que o homem organiza e processa as informações de forma dinâmica e evolutiva em torno de um Núcleo Central e de um conjunto de elementos periféricos (ABRIC, 1984; SÁ, 1996). De acordo com o pesquisador francês Jean-Claude Abric (1984, 1994), toda e qualquer representação é 
organizada em torno de um Núcleo Central, constituído de um ou mais elementos, que dão à representação o seu significado e que ocupam, na estrutura desta representação, uma posição privilegiada. Todo o pensamento necessita, para garantir a identidade e a continuidade do grupo social a que se refere, de certo número de crenças, coletivamente engendradas e historicamente determinadas, que sejam "inegociáveis", isto é, que não possam ser postas em questão, por constituírem o fundamento do modo de vida e do sistema de valores do grupo (ALVES-MAZZOTTI, 2002).

O Núcleo Central é determinado, em parte, pela natureza do objeto representado e, em parte, pela relação que o sujeito, ou um grupo de pessoas, mantém com este objeto. Dessa forma, o Núcleo Central se constitui como um subconjunto da representação, composto de um ou mais elementos, cuja ausência desestruturaria a representação ou lhe daria uma significação completamente diferente (SÁ, 1996). Os atributos que compõem o Núcleo Central são marcados pela memória coletiva e são estáveis e resistentes à mudança. Sua função é gerar significação para as imagens. Em torno do sistema central da imagem, há o sistema periférico, constituído pelos atributos mais flexíveis, sensíveis ao contexto imediato. Sua função é permitir a adaptação à realidade, bem como a diferenciação do conteúdo e a proteção ao sistema central. Os sistemas periféricos estão mais próximos das práticas do cotidiano e sujeitos às mudanças (SÁ, 1996). Enquanto o Núcleo Central é historicamente marcado, coerente, consensual e estável, a representação da periferia é adaptativa, flexível e relativamente heterogênea em relação ao conteúdo (ABRIC, 1994).

A partir da revisão da literatura sobre a organização das imagens na memória, percebe-se que as pessoas organizam suas imagens em torno de alguns conceitos centrais, que vão dar significado ao objeto em análise e que compõem o núcleo de suas representações.

\section{Consumo consciente}

$\mathrm{O}$ ato de consumir é um processo individual e coletivo. É um ato simbólico carregado de significado, influenciado pelos valores culturais e individuais que norteiam a ação de cada um. As mercadorias são transfor- madas em bens simbólicos e capazes de indicar o status do usuário. Além disso, as mercadorias propiciam sonhos e satisfação emocional individual, através de seus signos, imagens e do seu poder simbólico (TAVARES, 2007).

A compulsão pelo consumo desenfreado tem trazido consequências muito negativas para o meio ambiente. O consumo em excesso tem levado a um descontrole dos recursos naturais, comprometendo a harmonia ambiental. A partir da percepção de que os atuais padrões de consumo estão nas raízes da crise ambiental, "[...] a crítica ao 'consumismo' passou a ser vista como contribuição para construção de uma sociedade sustentável" (PORTILHO, 2003, p. 44). O ato de consumir, além de trazer prazer, pode trazer alguma preocupação para o sujeito (LEITE, 2009). Esta preocupação com as consequências do seu consumo também pode ser chamada de consumo consciente. O consumo consciente é um modo de vida que valoriza a responsabilidade ambiental como forma de preservar e manter um meio social com maior qualidade de vida (LEITE, 2009).

Dessa forma, observa-se que o consumo consciente transcende o bem-estar individual. O consumidor consciente é aquele que busca um equilíbrio entre o "eu" e o "outro", neste caso o meio ambiente. Assim, a preocupação também está com outras pessoas, com as gerações futuras e com a expectativa de estar contribuindo com a melhoria da qualidade de vida de todos (ANDERSON Jr. e CUNNINGHAM, 1972; LEITE, 2009). O tripé da questão do consumo verde está relacionado às questões da lucratividade, da qualidade do ambiente e da justiça social (CRONING et al., 2011).

Salienta-se que a principal força não será na redução do consumo. Isso seria provavelmente um exercício fútil. Muito mais importante é mudar a natureza do consumo em direção a produtos mais amigáveis ao ambiente, capazes de prosperar como parte de uma estratégia de desenvolvimento sustentável. Neste contexto, o marketing enquanto uma disciplina social pode contribuir na promoção cada vez maior do consumo consciente (HOLLIDAY et al., 2002).

Algumas pesquisas apontam para mudanças nos hábitos de compra e de consumo e indicam um crescimento do "marketing verde", com a difusão da consciência ecológica. Há uma mudança nos hábitos de compra e de consumo com o propósito de proteger o 
ambiente, repercutindo na participação em programas de reciclagem ou de reutilização de materiais, destacando-se o desejo do consumidor em pagar mais por produtos ecologicamente corretos ou os chamados produtos verdes (KEESLING e KAYNAMA, 2003; LEITE, 2009).

\section{Produtos ecologicamente corretos ou produtos verdes}

Com a difusão da consciência ecológica, da preocupação com o meio ambiente e com a qualidade de vida, há um crescimento do "Marketing Verde" ou produtos ecologicamente corretos (KEESLING e KAYNAMA, 2003; LEITE, 2009). Assim, o conceito de consumidor verde ou ecologicamente correto está relacionado ao indivíduo que busca conscientemente produzir, por meio do seu comportamento de consumo, um efeito nulo ou favorável sobre o meio ambiente e à sociedade como um todo (LAGES e VARGAS NETO, 2002).

O consumo de produtos ecologicamente corretos, segundo Scherer e Poledna (2002), é aquele que observa os impactos que um produto pode exercer no meio ambiente, havendo uma preocupação com o bem-estar social e ambiental. Ottman (2012) indica que os bens ecologicamente corretos, ou verdes, são aqueles que geram menos impacto ao meio ambiente do que seus alternativos.

A partir da revisão de diferentes pesquisadores, Motta (2002) e Motta e Mattar (2011) indicam que produto ecologicamente correto se caracteriza pelos seguintes aspectos: (i) fabricado com matérias-primas renováveis, recicláveis e que conservem recursos naturais quando extraídas, com a quantidade mínima de matérias-primas, com a máxima eficiência energética e de utilização de água e com o mínimo despejo de resíduos em efluentes; (ii) acondicionado em embalagens mais leves, mais volumosas, cujos rótulos provêm informações sobre o produto e cujos materiais são renováveis e recicláveis; (iii) é durável, prestando-se a múltiplos propósitos, podendo ser facilmente consertado e desmontado, oferece mais segurança, oferece maior eficiência energética e conserva recursos naturais quando é utilizado, é reutilizável, pode ser refabricado e atualizado, é biodegradável, pode ser substituído por refil ou equivalente; (iv) propicia descarte seguro; (v) é compostável, incinerável ou reciclável; (vi) pode ser transportado com o menor impacto possível ao ambiente; e (vii) fabricado de forma sustentável.

Nota-se que há uma grande proliferação dos produtos ecologicamente corretos, muito em função das pressões advindas da sociedade e, sobretudo, de seus consumidores, que anseiam por posturas socioambientais mais proativas. Entre os exemplos, estão tintas fabricadas sem solventes, geladeiras que consomem menos energia elétrica, alimentos orgânicos, como arroz, café, hortifrutigranjeiros e azeites, lápis, móveis e ferramentas com madeira certificada, papéis reciclados e cosméticos com ingredientes naturais (MOTTA e MATTAR, 2011).

Organizações que se engajam em práticas verdes podem se beneficiar de diferentes maneiras. As empresas podem ter uma maior participação de mercado, maior nível de comprometimento de seus empregados, aumento da performance e de suas capacidades. $\mathrm{O}$ grande número de oferta de produtos verdes que surgem no mercado se deve, em parte, a uma maior preocupação com o meio ambiente. Dessa forma, empresas que utilizam a questão do "verde" como uma estratégia inovadora desenvolvem um modo efetivo de reduzir o desperdício, criar novas embalagens e processos de produção e desenvolver melhores modos de distribuir seus produtos e serviços ao consumidor (CRONING et al., 2011). No entanto, Pickett-Baker e Ozaki (2008) indicam que muitos consumidores não conseguem identificar claramente os produtos verdes, o que encaminha à necessidade de uma maior atuação da área de marketing para torná-los mais conhecidos, indicando ainda seus reais benefícios para o meio ambiente.

Dessa forma, Trust e Chen (2010) afirmam que há cinco razões para que as empresas adotem um marketing verde: (i) observação das pressões com as questões ambientais; (ii) obtenção de possível vantagem competitiva; (iii) melhoria da imagem corporativa; (iv) procura por novos mercados ou oportunidades; e (v) melhoria no valor do produto. Uma clientela mais conscientizada, uma legislação mais rigorosa e empregados mais ligados ao meio ambiente abriram novas oportunidades na comercialização de produtos e serviços (JÖHR, 1994). O movimento do consumo verde mundial é visto como uma oportunidade de mercado e esforços de marketing têm sido desenvolvidos para a criação e promoção de produtos e/ou serviços com apelos ecológicos. 
Como um contraponto, a partir de uma visão mais crítica em relação à massificação dos produtos chamados "ecologicamente corretos", Tavares (2007) comenta que isso pode ser mais uma jogada mercadológica para atrair mais consumidores para um novo tipo consumo e não para a racionalização ou crítica ao consumo desenfreado. O mesmo autor ainda destaca que os consumidores brasileiros veem os produtos ecologicamente corretos como associados à saúde, ao bem-estar (prazer) e a uma qualidade de vida melhor. Para os consumidores, a escolha de produtos com apelos ecológicos tem motivação individual, numa interpretação em que natureza é uma "mercadoria", associada a um estilo de vida relacionado ao prazer e à saúde - a proteção da natureza não parece se constituir como a principal motivação para essa escolha. Ou seja, fazer o bem à natureza é, também e principalmente, fazer um bem a si mesmo: nesse sentido, a natureza surge como meio e não um fim neste raciocínio. A lógica do consumo consciente não enverga para a racionalização do consumo, mas sim para a manutenção e ampliação do consumo a partir de uma nova roupagem, chamada de "consumidor verde" (TAVARES, 2007).

Sendo assim, com o desenvolvimento desse mercado e o aumento da visibilidade da temática ambiental, surgem oportunidades para os produtos verdes, ecoprodutos ou environment friendly products, que sinalizam e refletem um novo paradigma de consumo (TAVARES, 2007). Por isso, o consumo verde passa a gravitar em torno da criação e implementação de estratégias e ações ambientalmente responsáveis e produtos ecologicamente corretos, com os objetivos fundamentais de assegurar, entre outros aspectos, uma imagem positiva da empresa e da captação de lucros com esses esforços realizados, por meio da venda desses produtos (OTTMAN, 2012).

Além disso, quanto mais consciente o consumidor, maior sua percepção de valor (qualidade e benefícios percebidos) do que o sacrifício (pagar mais caro) em relação aos produtos verdes (CHANG e FONG, 2010). Portanto, consumidores com uma forte consciência voltada para o aspecto ambiental acreditam que produtos verdes apresentam mais benefícios que sacrifícios (PICKETT-BAKER e OZAKI, 2008).

A partir dos conceitos apresentados, observa-se que o conceito de consumo consciente é mais amplo que o de consumo de produtos ecologicamente corre- tos. Enquanto o consumo de produtos ecologicamente corretos refere-se a uma visão ambiental na escolha por produtos, o consumo consciente envolve uma mudança nas escolhas individuais, não tão somente a preocupação com o ambiente, mas também com variáveis mais coletivas (SILVA, 2012). Todavia, o consumo de produtos ecologicamente corretos ou produtos verdes é um caminho para o consumo consciente e, posteriormente, para o consumo sustentável, cuja preocupação transcende a individual e passa necessariamente para uma preocupação socioambiental (SILVA, 2012).

\section{A multidimensionalidade do conceito de produtos ecologicamente corretos}

Diversos autores, em várias disciplinas, tais como psicologia, antropologia, biologia e sociologia, tratam do desenvolvimento humano como o despertar progressivo da consciência para os vários níveis de realidade que compõem a existência. Conforme Schuler, De Toni e Milan (2009), todas as manifestações humanas, bem como a manifestação de consumo consciente, gozam da complexidade multidimensional e, se forem analisadas sem considerar suas várias dimensões, não se revelarão de forma satisfatória ao entendimento do fenômeno. Quando se propõe analisar uma imagem mental, então, necessita-se levar em conta as informações e as percepções de cada uma dessas dimensões para se obter uma reconstituição mais acurada das considerações que os indivíduos organizam e como representam o objeto em questão (BURKE e EDELL, 1989).

Dessa forma, identifica-se que as imagens ou percepções são compostas por diferentes dimensões (DE TONI, 2005; SCHULER, DE TONI e MILAN, 2009). Por conseguinte, a partir da revisão da literatura sobre imagem e sobre o conceito de produtos ecologicamente corretos, pode-se inferir que as dimensões que melhor fundamentam este conceito são, respectivamente: a dimensão simbólica, manifestada predominantemente pela consciência ecológica; a dimensão racional, em que apresenta uma percepção focada na economia de recursos; a dimensão funcional, calcada na reutilização dos produtos e reciclagem; e a dimensão axiomática, em 
que manifesta um valor fundamentalmente baseado na vida saudável e no bem-estar social e individual.

A dimensão simbólica corresponde ao processo de representação do pensamento em signos, por meio dos quais o sujeito representa e interpreta o mundo. Lida com o objeto de forma abstrata, simbólica. É a partir daí que o sujeito está apto a realmente lidar com este objeto, de forma abstrata, na forma de signo. Quando um signo é disposto no repertório de um sujeito, é categorizado, gerando ligações mais próximas com os signos já presentes no repertório, se aproximando deles, quer por semelhança, quer por várias outras operações de significação, tais como a metáfora e a analogia. Na dimensão simbólica podem estar presentes os atributos extrínsecos do produto, como, por exemplo, marca e reputação do fabricante e o que representam para o comprador. Desta forma, um indivíduo, ao estar em contato com um objeto, também considera os seus atributos simbólicos, ou seja, aquilo que significa ou representa para ele (LEVY, 1981; DICHTER, 1985; MARTINEAU, 1958). No que se refere a produtos ecologicamente corretos, a dimensão simbólica pode estar relacionada à consciência ecológica do indivíduo, sendo que a consciência ecológica retrata a fase de aquisição, indicando a preferência dos consumidores por produtos, serviços, empresas e políticos ecologicamente corretos. Esta dimensão é apoiada a partir de atitudes que mobilizam os indivíduos com relação aos cuidados com o meio ambiente e a prática do consumo consciente (RIBEIRO e VEIGA, 2011; AKATU, 2007; GONÇALVES-DIAS et al., 2009; LEE e HOLDEN, 1999).

Em um nível mais mental de percepção, tem-se a dimensão racional, na qual o indivíduo tem um maior nível de troca de informações com o ambiente, resultando em uma maior compreensão e profundidade do seu conteúdo. Tal nível mental de percepção deixa um resíduo intelectual, municiando a razão para avaliações de ordem pragmática, funcional e lógica. Ele vai gerar os atributos racionais do objeto, que estarão disponíveis ao pensamento para realizar todas as suas operações básicas de análise, síntese, inferência e tantas outras. O sistema cognitivo cria redes de conhecimento que organizam e ligam vários tipos de informação, trazendo significado aos objetos (MARTINEAU, 1958; DICHTER, 1985).
O aspecto cognitivo desta dimensão pressupõe que o indivíduo tenha conhecimento suficiente para avaliar a funcionalidade do produto adquirido e de como compará-lo, em termos de eficiência, com o que está sendo ofertado no mercado (LAZARUS, 1991). A percepção racional de produtos ecologicamente corretos pode ser manifestada a partir da busca de informações sobre os produtos, verificando se os mesmos auxiliam ou não na preservação do meio ambiente, se apresentam uma maior economia de energia ou alguma economia de outro recurso natural. Assim, nesta dimensão, a economia de recursos indica a fase do uso, tendo como destaque a racionalização ou a redução do desperdício de recursos, tais como água e energia elétrica. Busca-se, também, uma maior utilização dos meios alternativos de transporte, tais como caminhadas, bicicleta e transporte coletivo em substituição ao automóvel (LAGES e VARGAS NETO, 2002; RIBEIRO e VEIGA, 2011; GONÇALVES-DIAS et al., 2009; AKATU, 2007).

$\mathrm{Na}$ dimensão em nível de percepção funcional, o conceito de produtos ecologicamente corretos se manifesta mediante todas as realidades alcançáveis pelos sentidos e pelas sensações humanas. Do ponto de vista pessoal, é o valor do enraizamento no mundo físico que o produto proporciona aos hábitos, usos, costumes e crenças (saúde, higiene, abundância, ecologia) e da possibilidade de "sobrevivência" que o produto oferece (SCHULER, DE TONI e MILAN, 2009). Estão aí contidas, também, as percepções de reciclagem e frugalidade do produto. Esta etapa lembra os cuidados com o meio ambiente no fim do ciclo de vida dos produtos e refere-se sobre o comportamento ambiental. A reciclagem refere-se mais especificamente ao comportamento de separação dos produtos descartados para serem reaproveitados novamente, podendo implicar, ou não, em um retorno imediato para o consumidor (AKATU, 2007; RIBEIRO e VEIGA, 2011; THAPA, 1999; LAGES e VARGAS NETO, 2002; GONÇALVES-DIAS et al., 2009; OTTMAN, 2012; PICKETT-BAKER e OZAKI, 2008). Já a frugalidade se refere à compra de produtos usados e à preocupação em reutilizar os produtos sempre que possível. Frugalidade representa a propensão a um estilo de vida mais simples, menos consumista, o que implica comportamentos ambientalmente favoráveis e na otimização racional de recursos (SHAW e MORAES, 
2009; RIBEIRO e VEIGA, 2011; AKATU, 2007; LAGES e VARGAS NETO, 2002; GONÇALVES-DIAS et al., 2009; DE YOUNG, 2000).

A dimensão axiomática da percepção, ou seja, aquele nível que envolve os principais valores que um objeto representa para as pessoas, de modo que ela o procura e adota quando percebe que, por meio dele, consegue exercer, no mundo, na sociedade, seus princípios pessoais de existência (HENRY, 1976; ROEHRICH, VALETTE-FLORENCE e RAPACCHI, 1989; BEATTY et al., 1985; BEATTY et al., 1996), é um nível ligado ao sentido da existência de uma pessoa (significado da vida) e à sua percepção de propósito e de valores e princípios. A própria expressão "produtos ecologicamente corretos" é uma manifestação axiomática do ato de observar e de se preocupar com a saúde e o bem-estar social e do meio ambiente (SCHERER e POLEDNA, 2002). Dessa forma, as manifestações axiomáticas podem estar presentes na percepção da importância de que tais produtos sejam em benefício da sociedade, que agridam menos o meio ambiente e sejam saudáveis.

Essa análise da forma como as pessoas percebem um objeto pode dar uma ideia da complexidade que significa e representa o sistema de informações que se cria na mente das pessoas para descrever e representar tal objeto, em sua tomada de decisão futura de como agir a seu respeito (compra, uso, consumo, descarte) (DE TONI, 2005). As informações que compõem este modelo mental pertencem a diversas dimensões, todas elas importantes e influentes na ação de quem percebe. Estas dimensões compõem, juntas, sinergicamente, como em um holograma, uma figura que aborda o objeto sob vários pontos de vista para constituir uma imagem mais completa e flexível. Esta imagem, por apresentar os vários aspectos (dimensões) que compõem o objeto, é multidimensional (SCHULER, DE TONI e MILAN,2009).

\section{Método de pesquisa}

Este estudo de natureza exploratória descritiva foi aplicado junto a estudantes de graduação em Administração de uma universidade comunitária e a empregados das áreas produtivas de três empresas do setor metal-mecânico, com atuação nacional e internacional, situadas em dois municípios da Serra Gaúcha. O curso de Administração em questão conta com 1.200 alunos matriculados e o número total de empregados da área produtiva das três empresas é de 850 . Levou-se em conta a amostragem não probabilística por conveniência, permitindo que um grande número de respondentes (por exemplo, acima de 150) fosse entrevistado em um espaço relativamente curto de tempo (HAIR Jr. et al., 2009).

Participaram da pesquisa 339 pessoas, sendo 207 estudantes de graduação e 132 empregados das áreas produtivas envolvidas. Mesmo com a amostragem sendo por conveniência e não probabilística, a escolha dos dois públicos se deu pelas possibilidades de encontro de diferenças e semelhanças que pudessem esclarecer e enriquecer a análise de aspectos atinentes à imagem relativa a produtos ecologicamente corretos. Foram escolhidos os estudantes de uma universidade com atuação regional e empregados com até ensino médio de empresas representativas de setores importantes da região. Os questionários estruturados foram coletados junto à amostra de forma pessoal, por meio do autopreenchimento dos participantes. Os estudantes responderam em sala de aula, em disciplinas escolhidas aleatoriamente. Os empregados das áreas produtivas responderam nos momentos de folga, em áreas apropriadas nas empresas. A coleta de dados ocorreu de outubro a novembro de 2011.

\section{O Método de Configuração de Imagem (MCI)}

A partir do objetivo de pesquisa, que é o de entender o processo de configuração da imagem de produtos ecologicamente corretos, foram estabelecidos a partir do MCI os seguintes procedimentos para a análise dos dados: identificar os atributos que formam a imagem de consumo consciente junto aos entrevistados, analisar a centralidade destes atributos na composição da imagem e identificar a multidimensionalidade da imagem relativa a produtos ecologicamente corretos.

O MCI se baseia em distintos métodos já desenvolvidos e validados (DE TONI, 2005, 2009; DE TONI e SCHULER, 2007). Dentre as diferentes etapas contempladas, o MCI propõe uma abordagem denominada configuração de conteúdo, alicerçada: (i) na identificação 
dos atributos salientes da imagem de um determinado objeto na mente dos respondentes; (ii) a atribuição de valores de ordem (VO) e valores de frequência (VF) aos atributos citados, visando à determinação das suas distâncias em relação ao termo empregado para estimular os respondentes a se manifestarem sobre o objeto pesquisado (termo indutor); e (iii) identificação da configuração das imagens de preço de produto a partir das suas dimensões.

Este procedimento costuma ser feito a partir de uma questão geral, seguido de uma questão para cada dimensão da imagem do objeto de pesquisa. No entanto, como a identificação destas dimensões já foi testada em um estudo anterior (SCHULER et al., 2010), optou-se por fazer apenas uma questão que buscasse, mesmo que de forma não tão profunda, identificar como se configura a imagem de produtos ecologicamente corretos.

Assim sendo, partiu-se da seguinte questão central de pesquisa: "Quando você pensa ou ouve falar em produtos ecologicamente corretos, que ideias ou palavras vêm à sua mente?". Cabe ressaltar que esta questão norteadora é uma adaptação da forma de entrevista do MCI desenvolvida no estudo de Schuler, De Toni e Milan (2009), a qual já foi previamente testada.

Tal como propõe o MCI, quanto à análise dos resultados, o tratamento dos dados foi realizado por meio da análise de conteúdo das respostas geradas a partir da questão apresentada. A análise de conteúdo obedeceu à seguinte ordem. Inicialmente, foram listadas todas as ideias mencionadas pelos respondentes, gerando os atributos pertinentes à imagem de produtos ecologicamente corretos. Em seguida, os atributos mencionados foram categorizados a partir da análise dos atributos por três pesquisadores com experiência na categorização, tal como pressupõe a técnica de juízes que visa dar mais validação ao conteúdo (MALHOTRA, 2011). Esta categorização ocorreu a partir das dimensões apresentadas na revisão da literatura, ou seja: dimensões simbólica, racional, funcional e axiomática.

\section{Resultados da pesquisa}

Os respondentes da pesquisa (339 participantes) apresentam as seguintes características: 207 são estu- dantes de graduação e 132 são trabalhadores do setor produtivo com até ensino médio completo; $59,7 \%$ do sexo feminino; $43,7 \%$ com até 24 anos e $49,1 \%$ com 25 a 40 anos; com relação à renda familiar mensal, 47,7\% possuem uma renda de até $\mathrm{R} \$ 2.000$ e $40,1 \%$ de $\mathrm{R} \$$ $2.001,00$ a 5.000,00. Da amostra, 33\% dos participantes pagariam de um a três por cento a mais por produtos ecologicamente corretos, $22,1 \%$ de quatro a cinco por cento e $44,8 \%$ o índice de seis por cento ou mais.

Considerando a caracterização de estudantes e de empregados das áreas produtivas, foram identificados entre os dois grupos diferenças significantes (teste de qui quadrado $-\chi^{2}$ ) ao nível de 0,05 para nível de instrução, idade e renda. $\mathrm{Na}$ amostra investigada os empregados apresentam instrução e renda menores e idade maior que os estudantes.

\section{Configuração da imagem de produtos ecologicamente corretos}

A partir de uma questão aberta em que o respondente foi convidado a escrever tudo o que vem à sua mente sobre o objeto de pesquisa, no caso desta pesquisa, de produtos ecologicamente corretos, foi realizada uma análise de conteúdo das respostas dadas à questão aberta. Assim, a partir das respostas dos 339 entrevistados, emergiram 518 citações divididas em mais de 31 atributos, sendo que, do total de citações, 336 foram de estudantes e 182 de trabalhadores. Esta fase do tratamento dos dados foi a mais delicada e necessitou habilidade para extrair a essência da ideia expressa pelos respondentes. Numa segunda etapa, foi categorizada para cada atributo a dimensão que mais predomina. Para isso, três pesquisadores, com experiência no estudo de imagens, categorizaram primeiro de forma independente e depois conjuntamente os atributos de acordo com as quatro dimensões propostas.

Na segunda etapa, os atributos gerados sofreram então um primeiro tratamento, onde foram levantadas a sua frequência e a sua ordem de aparição. Este tratamento foi proposto inicialmente por Abric (1984) e Puig-Vergès (1987) e visa criar uma distinção entre os atributos mais próximos e os mais distantes do Termo Indutor. Os mais próximos serão considerados como pertencentes 
à Imagem Central e os mais distantes serão localizados nas Imagens Intermediárias (Primeira e Segunda Imagem Intermediária) e na Periferia da Imagem. Assim, o Valor de Frequência (VF) é o número total de vezes que cada atributo foi citado. O Valor de Ordem (VO) é obtido pela atribuição de pesos decrescentes aos cinco primeiros atributos evocados pelo entrevistado. Para cada atributo citado em primeiro lugar, atribui-se o valor cinco, o que foi citado em segundo lugar recebe valor quatro, o que foi citado em terceiro lugar recebe valor três, o citado em quarto lugar recebe valor dois e o quinto atributo citado recebe valor um. Após o quinto citado, os atributos não mais recebem $\mathrm{VO}(\mathrm{VO}=0)$, apenas o VF. Na sequência, procedeu-se a um somatório simples dos valores conferidos aos atributos, gerando o VT, que é representado por: $\mathrm{VT}=\mathrm{VF}+\mathrm{VO}$.

Como analisado na literatura, toda e qualquer representação é organizada em torno de um núcleo ou imagem central e que dá significado à representação, ocupando uma posição privilegiada na mente dos pesquisados. Já os atributos que pertencem às periferias são mais flexíveis e sujeitos às mudanças, cuja função é permitir a adaptação à realidade (ABRIC, 1984; SÁ, 1996). Desta forma, a Imagem Central é mais comum, mais frequente e prontamente lembrada nas representações dos pesquisados, enquanto as imagens intermediárias e periféricas são elementos mais particularizados. Para gerar diferentes áreas de proximidade com o estímulo dado para evocar a imagem do produto junto à amostra (Termo Indutor), tal como propõe o MCI (DE TONI, 2005), aplicou-se a divisão por quartis ao conjunto de VTs encontrados. Dessa forma, foi possível identificar quatro grupos de atributos, considerando-se a Periferia da Imagem como composta pelo primeiro quartil, a Segunda Imagem Intermediária como formada pelo segundo quartil, a Primeira Imagem Intermediária como representada pelo terceiro quartil e a Imagem Central do conceito (produtos ecologicamente corretos) como sendo o conjunto de atributos com maior VT, que estão contidos no quarto quartil. A Tabela 1 é elucidativa.

A partir da análise dos atributos gerados, identifica-se que para os 339 entrevistados os atributos que com- põem a Imagem Central das suas representações e que dão significado ao conceito de produtos ecologicamente corretos são: "preservação do meio ambiente", "reciclagem”, "produtos sem agrotóxicos", "produtos saudáveis", "sustentabilidade", "bem-estar", "meio ambiente e natureza" e "futuro melhor". Tais atributos, associados na maioria a palavras de cunho mais abrangente, correspondem a quase $75 \%$ do valor total. Destaque também a dois itens associados mais com produtos alimentícios (produtos sem agrotóxicos e saudáveis).

Verificou-se, ainda, que os entrevistados relacionam produtos ecologicamente corretos com algo positivo. Em uma análise destes atributos, pode-se compor a seguinte descrição: produtos ecologicamente corretos são produtos saudáveis, sem agrotóxicos, sustentáveis e recicláveis, que preservam o meio ambiente e são capazes de proporcionar um futuro melhor e bem-estar à humanidade.

Tal conceito faz parte das representações sociais do público entrevistado e que pode servir de direcionamento estratégico na comunicação de marketing que vise proporcionar um melhor entendimento do conceito e, se for o caso, redirecionar tal conceito para novos rumos de acordo com os objetivos de marketing das empresas.

A Tabela 2 apresenta uma análise segmentada a partir da análise dos atributos que compõem a imagem central das representações dos estudantes e trabalhadores entrevistados.

A partir da Tabela 2, observa-se que de modo geral a configuração da imagem central, tanto para os estudantes quanto para os trabalhadores, é semelhante. Apenas os atributos "Meio ambiente e natureza" e "Futuro Melhor" não fazem parte da imagem central das representações dos trabalhadores. Ao invés disso, eles incluíram o "bem-estar" como um forte componente relacionado aos produtos ecologicamente corretos. O atributo "futuro melhor" foi muito pouco citado pelos trabalhadores (quatro vezes, contra 18 dos estudantes). Parece que os trabalhadores estão mais preocupados com o bem-estar no presente e que os produtos ecologicamente corretos auxiliam a preservar o meio ambiente como forma de lhe proporcionar bem-estar e saúde nesta geração e não apenas para as gerações futuras. 
TABELA 1 - CONFIGURAÇÃO DA IMAGEM DO CONCEITO DE PRODUTOS ECOLOGICAMENTE CORRETOS

\begin{tabular}{|c|c|c|c|c|c|c|c|c|}
\hline Níveis da Imagem & & Atributos da Imagem & VF & VO & VT & $\% / \mathrm{VT}$ & Total & Dimensão \\
\hline \multirow[t]{6}{*}{ Imagem Central } & 1 & Preservação do Meio Ambiente & 137 & 629 & 766 & 27,39 & 27,39 & Simbólica \\
\hline & 2 & Reciclagem & 61 & 275 & 336 & 12,01 & 39,40 & Funcional \\
\hline & 4 & Saúde: produtos saudáveis & 46 & 194 & 240 & 8,58 & 56,63 & Axiomática \\
\hline & 5 & Sustentabilidade & 25 & 114 & 139 & 4,97 & 61,60 & Axiomática \\
\hline & 7 & Meio Ambiente e Natureza & 22 & 102 & 124 & 4,43 & 70,65 & Racional \\
\hline & 8 & Futuro Melhor & 22 & 90 & 112 & 4,00 & 74,65 & Simbólica \\
\hline \multirow[t]{6}{*}{ Primeira Imagem } & 9 & Conscientização & 20 & 78 & 98 & 3,50 & 78,16 & Simbólica \\
\hline & 10 & Preocupação com o Meio Ambiente & 17 & 78 & 95 & 3,40 & 81,55 & Simbólica \\
\hline & 11 & Menor Impacto na Natureza & 9 & 43 & 52 & 1,86 & 83,41 & Simbólica \\
\hline & 14 & Produtos Corretos & 7 & 31 & 38 & 1,36 & 88,06 & Funcional \\
\hline & 15 & Normas Exigidas & 7 & 30 & 37 & 1,32 & 89,38 & Racional \\
\hline & 16 & Respeito ao Meio Ambiente & 8 & 27 & 35 & 1,25 & 90,63 & Simbólica \\
\hline \multirow[t]{6}{*}{ Segunda Imagem } & 17 & Menor consumo de energia & 6 & 26 & 32 & 1,14 & 91,78 & Racional \\
\hline & 18 & Responsabilidade Social e Ambiental & 6 & 24 & 30 & 1,07 & 92,85 & Simbólica \\
\hline & 19 & Ar Puro & 5 & 23 & 28 & 1,00 & 93,85 & Funcional \\
\hline & 20 & Ecologicamente Corretos & 4 & 19 & 23 & 0,82 & 94,67 & Simbólica \\
\hline & 21 & Água Potável & 5 & 17 & 22 & 0,79 & 95,46 & Funcional \\
\hline & 22 & Rápida Decomposição & 4 & 17 & 21 & 0,75 & 96,21 & Funcional \\
\hline \multirow{5}{*}{ Periferia } & 28 & Economia & 2 & 9 & 11 & 0,39 & 99,11 & Racional \\
\hline & 29 & Reflorestamento & 2 & 8 & 10 & 0,36 & 99,46 & Funcional \\
\hline & 30 & Energia Limpa & 2 & 6 & 8 & 0,29 & 99,75 & Racional \\
\hline & 31 & Amor ao Próximo & 2 & 5 & 7 & 0,25 & 100,00 & Axiomática \\
\hline & & Total & 518 & & 2797 & & & \\
\hline
\end{tabular}

FONTE: Elaborada pelos autores. 
TABELA2 - IMAGEM CENTRAL DO CONCEITO DE PRODUTOS ECOLOGICAMENTE CORRETOS POR GRUPO DE PARTICIPANTES DA PESQUISA

\begin{tabular}{|l|l|l|}
\hline N. & Estudantes & Trabalhadores \\
\hline 1 & $\begin{array}{l}\text { Preservação do Meio } \\
\text { Ambiente }\end{array}$ & $\begin{array}{l}\text { Preservação do Meio } \\
\text { Ambiente }\end{array}$ \\
\hline 2 & Reciclagem & Reciclagem \\
\hline 3 & $\begin{array}{l}\text { Produtos sem } \\
\text { Agrotóxicos }\end{array}$ & $\begin{array}{l}\text { Produtos sem } \\
\text { Agrotóxicos }\end{array}$ \\
\hline 4 & $\begin{array}{l}\text { Saúde: Produtos } \\
\text { Saudáveis }\end{array}$ & $\begin{array}{l}\text { Saúde: Produtos } \\
\text { Saudáveis }\end{array}$ \\
\hline 5 & $\begin{array}{l}\text { Meio Ambiente e } \\
\text { Natureza }\end{array}$ & Sustentabilidade \\
\hline 6 & Futuro Melhor & Bem-estar \\
\hline 7 & Sustentabilidade & \\
\hline
\end{tabular}

FONTE: Elaborada pelos autores.

O peso de cada dimensão foi baseado a partir do percentual do VT, conforme pode ser visto na Figura 1.

Os resultados da categorização dos atributos a partir das quatro dimensões mostram que a dimensão simbólica, tanto na amostra geral (44\%) quanto no segmento de estudantes (49\%) e trabalhadores (38\%), é a mais representativa na imagem destes respondentes. Esta dimensão está fundamentada em uma perspectiva de preocupação e cuidados com o meio ambiente a partir de um consumo mais consciente. Assim, percebe-se que a dimensão simbólica está presente com maior intensidade nos estudantes.

A segunda dimensão com maior peso é a funcional, com uma média de $28 \%$ das manifestações. Nesta dimensão estão contidas as percepções de reciclagem e frugalidade, ou a preocupação com a reutilização dos produtos. Verificou-se também nesta dimensão uma diferença substancial na percepção de produtos ecologicamente corretos. Enquanto que para os estudantes a dimensão funcional representa $24 \%$ dos atributos mais frequentes e salientes, para os trabalhadores este percentual aumenta para 34\%. Com uma conotação mais prática, observa-se que, para os trabalhadores, uma relação do conceito de produtos ecologicamente corretos com, por exemplo, produtos sem agrotóxicos, produtos corretos, carros elétricos e ar puro, é mais prontamente lembrada do que para os estudantes.

A terceira dimensão com maior saliência nas representações da imagem de produtos ecologicamente corretos é a axiomática (18\%). Esta dimensão retrata uma preocupação com a saúde e o bem-estar social e ambiental. Não há uma diferença substancial entre os dois públicos investigados; dessa forma, uma relação direta de produtos ecologicamente corretos com produtos saudáveis para a vida e para o ambiente também é uma manifestação presente para os entrevistados.

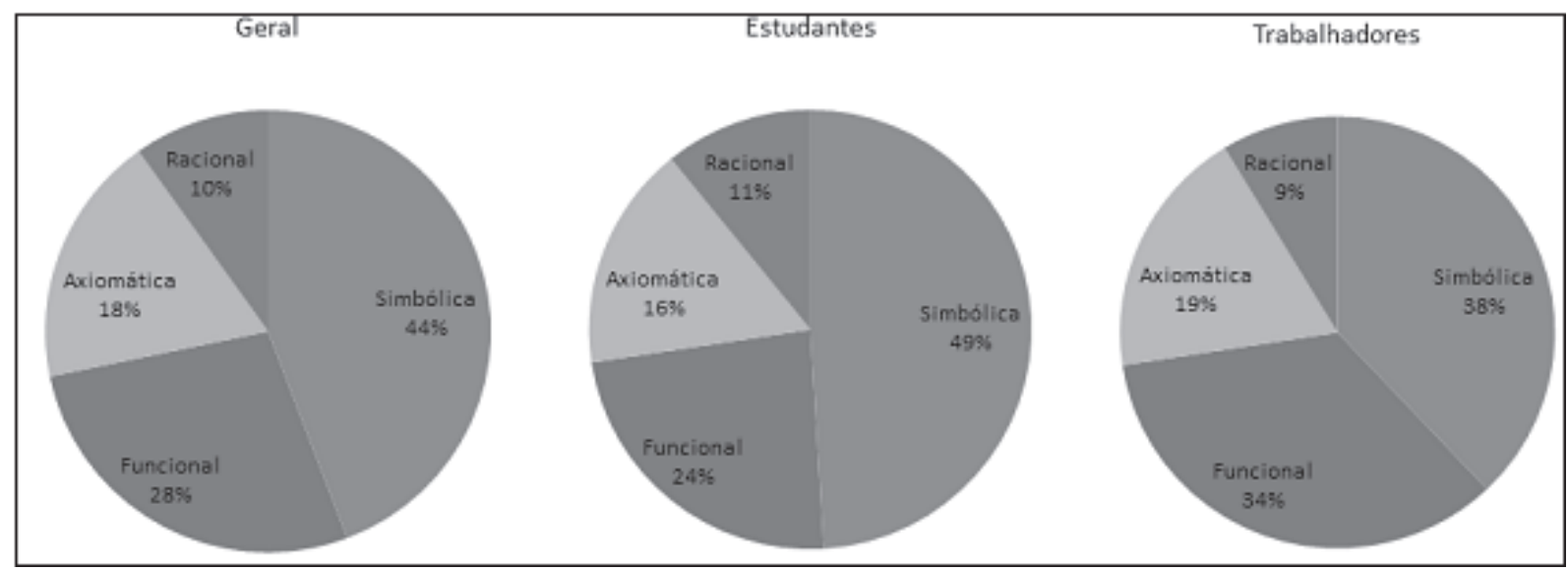

FIGURA 1 - Dimensões que compõem a imagem do conceito de produtos ecologicamente corretos. FONTE: Elaborada pelos autores. 
A quarta e última dimensão com menos destaque nas representações da amostra investigada é a racional $(10 \%)$. Nesta dimensão está contida uma preocupação racional voltada para a economia de energia e racionalização de recursos naturais que o produto ecologicamente correto pode proporcionar. Observa-se também que não houve diferença substancial na frequência e saliência da imagem dos estudantes e trabalhadores.

Percebe-se, portanto, que as diferenças mais evidentes entre os grupos de estudantes e de trabalhadores se dão entre as dimensões simbólica e funcional. $\mathrm{O}$ predomínio da dimensão simbólica nos estudantes possivelmente pode estar relacionado a um contato maior com materiais e discursos ligados à sustentabilidade e a uma preocupação maior com o longo prazo, visto que estão se preparando para o futuro. Já para os trabalhadores, predominam preocupações mais voltadas ao produto em si, aos aspectos de funcionalidade do produto.

Ao se considerar, como recomenda o MCI (DE TONI, 2009), que fazem parte da Imagem Central de um objeto aqueles atributos que são citados em maior número e em primeiro lugar, pode-se dizer que para os entrevistados a Imagem Central do conceito de produtos ecologicamente corretos, portanto, é formada essencialmente por atributos simbólicos, funcionais e axiomáticos. Desta maneira, os produtos ecologicamente corretos são percebidos como produtos saudáveis, sem agrotóxicos, sustentáveis e recicláveis que preservam o meio ambiente e proporcionam um bem-estar e futuro melhor à humanidade.

\section{Considerações finais}

A partir da revisão da literatura, identificou-se que produtos ecologicamente corretos são aqueles que observam os impactos que um produto pode exercer no meio ambiente buscando um bem-estar social e ambiental (SCHERER e POLEDNA, 2002). São produtos que conservam os recursos naturais, são recicláveis, retornáveis e duráveis (MOTTA e MATTAR, 2011). Observa-se que tal conceito está fundamentado mais fortemente numa dimensão funcional e racional; assim, este estudo amplia este conceito e agrega elementos simbólicos e axiomáticos.
Desse modo, por meio do Método de Configuração de Imagem (MCI), buscou-se compreender também este conceito a partir das representações dos estudantes de graduação e trabalhadores com até o ensino médio. Os achados desta pesquisa são importantes porque revelam como estão configuradas as imagens dos respondentes. Nesse sentido, identificaram-se a centralidade e a dimensionalidade da imagem de produtos ecologicamente corretos. Quanto à centralidade, ou seja, os atributos que dão maior significado ao objeto (conceito) pesquisado e que são os mais frequentes e salientes na mente dos pesquisados, observa-se pouca diferença entre os estudantes e trabalhadores. Desse modo, é possível dizer que a imagem central do conceito de produtos ecologicamente corretos está ligada à "preservação do meio ambiente", à "reciclagem", à ideia de "produtos sem agrotóxicos", de "produtos saudáveis", da "sustentabilidade", do "bem-estar" e ligada à preocupação com o "meio ambiente e natureza" e com um "futuro melhor". Além destes, há outros 23 atributos que também complementam o conceito de produtos ecologicamente corretos e que auxiliam a entender melhor como ele se configura nas representações do público pesquisado.

Como um conceito multidimensional, observou-se que ele se estrutura fundamentalmente a partir das dimensões simbólicas, funcionais e axiomáticas. Ou seja, a preocupação com o meio ambiente (e a sua preservação) e a visualização de um futuro melhor são atributos que identificam o simbolismo de que tais produtos podem contribuir para diminuir o impacto ambiental. Já as questões mais funcionais ou práticas do conceito também estão fortemente presentes nas representações, principalmente dos trabalhadores. Assim, a associação com a reciclagem, com produtos sem agrotóxicos, com produtos que consomem menos energia são representações que também fundamentam a funcionalidade do conceito estudado. A preocupação com a saúde, com o bem-estar e a sustentabilidade são princípios e valores que fundamentam a dimensão axiomática.

Dentre as principais contribuições do artigo, podem-se destacar duas: primeiro, que a pesquisa proporcionou um melhor entendimento e ampliação do conceito de produtos ecologicamente corretos, tanto de um ponto de vista teórico quanto do ponto de vista das representações dos entrevistados. A partir dos resultados 
da pesquisa exploratória, foi possível identificar que a imagem central do conceito de produtos ecologicamente corretos está relacionada a produtos saudáveis, sem agrotóxicos, sustentáveis e recicláveis, que preservam o meio ambiente e proporcionam um bem-estar e futuro melhor à humanidade. Uma segunda contribuição está na identificação da multidimensionalidade da imagem do conceito de produtos ecologicamente corretos. Entender essas múltiplas dimensões que formam um conceito é uma forma de ordenar a representação social de um conceito na mente do público-alvo da pesquisa. Ao se caracterizar quatro dimensões que compõem a imagem de produtos ecologicamente corretos, quer-se apresentar que a imagem do conceito de produtos ecológicos pode essencialmente ser configurada a partir de elementos funcionais, simbólicos, racionais e axiomáticos. Por outro lado, conforme Foxal (2001), a análise do comportamento do consumidor pode estar mais fortemente fundamentada em uma visão de interdependências que meramente em uma abordagem multidisciplinar ou multidimensional. Nesse sentido, futuras pesquisas podem estudar como estas dimensões se relacionam entre si, nesta perspectiva de interdependência. Evidenciou-se neste estudo que a multidimensionalidade não ocorre somente pela presença de mais de um constructo para explicar o fenômeno, ela também pode estar presente dentro de um mesmo atributo de forma interdependente. Assim, por exemplo, o atributo sustentabilidade pode remeter a um novo conjunto de

\section{Referências}

ABRIC, J. C. Theoretical and experimental approach to the study of social representations in a situation of interaction. In: FARR, R. M.; MOSCOVICI, S. (Eds.). Social representations. Cambridge: Cambridge University Press, 1984. p. 169-183.

Pratiques sociales et représentations. Paris: Presses Universitaires de France, 1994.

AKATU. Pesquisa Akatu n ${ }^{\circ}$ 7, 2006: como e por que os consumidores brasileiros praticam o consumo consciente? São Paulo: Instituto Akatu, 2007. Disponível em: <www.akatu. org.br/akatu_acao/publicacoes/perfi l-do-consumidor>. Acesso em: 15/02/2010. diferentes dimensões, podendo conter tanto elementos simbólicos quanto axiomáticos ou funcionais. Dessa forma, um mesmo atributo pode apresentar diferentes significados que, para entender melhor o seu conteúdo, necessitam estar relacionados ao contexto do público-alvo no qual sua representação é formada. Como afirma Vygotsky (1998, p. 190), "uma palavra é um microcosmo da consciência humana". Dessa forma, pode-se afirmar que cada atributo é um microcosmo de significados, podendo ser configurado tanto de forma multidimensional quanto de forma interdependente.

Por meio de um entendimento do que representa um conceito para diferentes públicos-alvo, é possível direcionar estratégias e ações de organizações governamentais, não governamentais e comerciais, que visem atingir melhor o consumidor pelo fortalecimento da imagem desejada, incluindo novos conceitos ou, até mesmo, pela modificação de conceitos ou imagens não desejadas. No caso desta pesquisa, a promoção de produtos ecologicamente corretos pode ser um importante trunfo das organizações, uma vez que todos os atributos apresentados pelos entrevistados são caracterizados como positivos, o que pode estimular sua divulgação e consumo de forma mais consciente. Consoante a isso, estratégias e ações empresariais e/ou institucionais que direcionem suas comunicações a partir da configuração mais adequada ao conceito identificado serão melhor compreendidas pelos consumidores, uma vez que fazem parte das representações deste público-alvo.

ALVES-MAZZOTTI, A. J. A abordagem estrutural das representações sociais. Psicologia da Educação, n. 14/15, p. 17-38, 2002.

ANDERSON Jr., W. T.; CUNNINGHAM, W. H. The socially conscious consumer. Journal of Marketing, v. 36, n. 3, p. 23-31, 1972.

BEATTY, S. E.; KAHLE L. R.; HOMER P.; MISRA S. C. Alternative measurement approaches to consumer values: the list of values and the Rokeach Value Survey. Psychology and Marketing, v. 2, n. 3, p. 181-200, 1985. 
; YOON, M. H.; GRUNERT, S. C.; HELGESON, J. G. An examination of gift-giving behaviors and personal values in four countries, in gift-giving: an interdisciplinary anthology. In: OTNES, C.; BELTRAMINI, R. (Eds.). OH: Bowling Green State University Popular Press, p. 19-36, 1996.

BOULDING, K. E. The image: knowledge in life and society. $6^{\text {th }}$ printing. Ann Harbor: University of Michigan, 1986.

BREAKWELL, G. M. Mental models and social representations of hazards: the significance of identity processes. Journal of Risk Research, v. 4, n. 4, p. 341-351, 2001.

BURKE, M. C.; EDELL, J. A. The impact of feelings on ad-based affect and cognition. Journal of Marketing Research, v. 26, n. 1, p. 69-83, 1989.

CHANG, N.; FONG, C. Green product quality, green corporate image, green customer satisfaction, and green customer loyalty. African Journal of Business Management, v. 4, n. 13, p. 2836-2844, 2010.

CRONING J.; SMITH, J. S.; GLEIM, M. R.; RAMIREZ, E.; MARTINEZ, J. D. Green marketing strategies: an examination of stakeholders and the opportunities they present. Journal of the Academy of Marketing Science, n. 39, p.158-174, 2011.

DE TONI, D. Administração da imagem de produtos: desenvolvendo um instrumento para a configuração da imagem de produto. Porto Alegre, Tese (Doutorado em Administração) - Universidade Federal do Rio Grande do Sul, 2005.

Administração da imagem de organizações, marcas e produtos. In: KUNSCH, M. M. K. (Org.). Comunicação organizacional: histórico, fundamentos e processos. São Paulo: Saraiva, p. 235-268, 2009.

; SCHULER, M. Gestão da imagem: desenvolvendo um instrumento para a configuração da imagem de produto. Revista de Administração Contemporânea, v. 11, n. 4, out.-dez. 2007.

DE YOUNG, R. Expanding and evaluating motives for environmentally responsible behavior. Journal of Social Issues, v. 56, n. 3, p. 509-523, 2000.

DICHTER, E. What's in an image. Journal of Consumer Marketing, v. 2, n. 1, p. 75-81, 1985.

DOBNI, D.; ZINKHAN, G. M. In search of brand image: a foundation analysis. Advances in Consumer Research, v. 17, n. 1, p. 110-119, 1990.

FOXAL, G. R. Foundations of consumer behavior analysis. Marketing Theory, v. 1, p. 165-199, 2001.
GONÇALVES-DIAS, S. L. F.; TEODÓSIO, A. S. S.; CARVALHO, S.; SILVA, H. M. R. Consciência ambiental: um estudo exploratório sobre suas implicações para o ensino de administração. Revista Eletrônica, v. 8, n. 1, art. 3, jan./jun. 2009.

HAIR Jr., J. et al. Análise multivariada de dados. Porto Alegre: Bookman, 2009.

HENRY, W. A. Cultural values do correlate with consumer behavior. Journal of Marketing Research, v. 13, n. 2, p. 121127, 1976.

HOLLIDAY, C. et al. Cumprindo o prometido: casos de sucesso do desenvolvimento sustentável. Rio de Janeiro: Campus, 2002.

JODELET, D. La representación social: fenómenos, conceptos y teoría. In: MOSCOVICI, S. (Ed.). Psicología social, el pensamiento y vida social. Barcelona: Paidós, 1988. p. 469-494.

El movimiento de retorno al sujeto y el enfoque de las representaciones sociales. Cultura y Representaciones Sociales, n. 5, p. 32-63, 2008.

JÖHR, H. O verde é negócio. São Paulo: Saraiva, 1994.

KEESLING, G.; KAYNAMA, S. An exploratory investigation of the ecologically conscious consumer's efforts to control water contamination lawn care and the use of nitrogen fertilizers and pesticides. Journal of Marketing Theory and Practice, v. 11, n. 1, p. 52-64, 2003.

LAGES, N. S.; VARGAS NETO, A. Mensurando a consciência ecológica do consumidor: um estudo realizado na cidade de Porto Alegre. In: ENCONTRO ANUAL DA ASSOCIAÇÃO NACIONAL DE PÓS-GRADUAÇÃO E PESQUISA EM ADMINISTRAÇÃO, 26., 2002. Salvador, Bahia: ANPAD. Anais.

LAZARUS, R. Progress on a cognitive-motivational-relational theory of emotion. American Psychologist, v. 46, p. 819-834, 1991.

LEE, J. A.; HOLDEN, S. J. Understanding the Determinants of Environmentally Conscious Behavior. Psychology \& Marketing, v. 16, n. 5, p. 373-392, 1999.

LEITE, P. R. Logística reversa: meio ambiente e competitividade. 2. ed. São Paulo: Pearson Prentice Hall, 2009.

LEVY, S. J. Interpreting consumer mythology: a structural approach to consumer behavior. Journal of Marketing, v. 45, n. 3, p. 49-61, 1981.

MALHOTRA, N. K. Pesquisa de marketing: foco na decisão. 3. ed. São Paulo: Pearson Prentice Hall, 2011. 
MARTINEAU, P. The personality of the retail store. Harvard Business Review, v. 36, n. 1, p. 47-55, 1958.

MORGAN, G. Imagens da organização: edição executiva. São Paulo: Atlas, 2000.

MOSCOVICI, S. A representação social da psicanálise. Rio de Janeiro: Zahar, 1978.

Social representation: explorations in social psychology. Cambridge: Polity Press, 2000.

MOTTA, S. L. S. A relevância da comunicação no composto de marketing de produtos ecologicamente corretos. Revista de Pesquisa Comunicare, São Paulo, v. 2, n. 2, 2002.

; MATTAR, F. N. Atitude em relação a atributos ecológicos de produtos como base de segmentação de mercado consumidor. Revista de Administração, v. 46, n. 1, art. 3, p. 32-44, 2011.

OTTMAN, J. A. As novas regras do marketing verde: estratégias, ferramentas e inspiração para um branding sustentável. São Paulo: Makron Books, 2012.

OYEWOLE, P. Social costs of environmental justice associated with the practice of green marketing. Journal of Business Ethics, v. 29, n. 3, p. 239-251, 2001.

PICKETT-BAKER, J.; OZAKI, R. Pro-environmental products: marketing influence on consumer purchase decision. Journal of Consumer Marketing, v. 25, n. 5, p. 281-293, 2008.

PORTILHO, M. F. F. O discurso internacional sobre consumo sustentável: possibilidades de ambientalização e politização da esfera privada. Campinas-SP, Tese (Doutorado) - Universidade Estadual de Campinas, 2003.

PUIG-VERGÈS, N. Aux sorces de la psychose: corporeitè et pensèe sychotique. Paris: Hommes et Groupes Editeurs, 1987. p. 407.

RIBEIRO, J. A.; VEIGA, R. T. Proposição de uma escala de consumo sustentável. Revista Administração, São Paulo, v. 46, n. 1, p. 45-60, jan./fev./mar. 2011.

ROEHRICH, G.; VALETTE-FLORENCE, P.; RAPACCHI, B. Combined influence of personal value systems, involvement and innovativeness on innovative consumer behavior: an application on perfume purchase. In: ESOMAR Seminar, p. 261-279, 1989.

SÁ, C. P. Sobre o núcleo central das representações sociais. Petrópolis: Vozes, 1996.

SCHERER, M.; POLEDNA, S. Marketing verde. In: ASSEMBLEIA DO CONSELHO LATINO-AMERICANO DE ESCOLAS DE ADMINISTRAÇÃO, 37., 2002. Porto Alegre: CLADEA. Anais.

SCHULER, M.; DE TONI, D.; MILAN, G. S. As dimensões da imagem mercadológica. In: MILAN, G. S. (Org.). Administração mercadológica: teoria e pesquisas. Caxias do Sul: EDUCS, n. 3, p. 247-273, 2009.

; LARENTIS, F. As dimensões da imagem de preço para o consumidor: uma abordagem exploratória. In: ENCONTRO ANUAL DAANPAD, 34., 2010. Rio de Janeiro: ANPAD. Anais.

SHAW, D.; MORAES, C. Voluntary simplicity: an exploration of market interactions. International Journal of Consumer Studies, v. 33, n. 2, p. 215-223, 2009.

SILVA, M. E. Consumo sustentável: a articulação de um constructo sob a perspectiva do desenvolvimento sustentável. Revista Eletrônica de Ciências Administrativas (RECADM), v. 11, n. 2, 2012.

TAVARES, F. A. Jr. Natureza S/A? O consumo verde na lógica do ecopoder. Rio de Janeiro, Tese (Doutorado) - Programa de Pós-Graduação em Psicossociologia de Comunidades de Ecologia Social (EICOS), Instituto de Psicologia da Universidade Federal do Rio de Janeiro, 2007. p. 183-188.

THAPA, B. Environmentalism: the relation of environmental attitudes and environmentally responsible behaviors among undergraduate students. Bulletin of Science, Technology \& Society, Thousand Oaks, v. 19, n. 5, p. 426-438, 1999.

TRUST, G.; CHEN, Y. Towards Green Loyalty: Driving from Green Perceived Value, Green Satisfaction, and Green Trust. Sustainable Development, p. 1-15, 2010.

VYGOTSKY, L.S. Pensamento e linguagem. São Paulo: Martins Fontes, 1998.

Recebido em 04 de março de 2013. Aceito em 22 de maio de 2013. Publicado em dezembro de 2013. 